\section{From the Co-Editors...}

Dear JSESD Readers and Supporters,

We continue to be very pleased with the response to the revamped online and open access issues of the Journal of Science Education for Students with Disabilities (JSESD). We are pleased that JSESD in this format maximizes access for readers and authors, will help the journal continue to grow, and will allow the journal to remain economically sustainable.

A couple reminders:

- The journal will reside online and free-of-charge on Rochester Institute of Technology's (RIT) Wallace Library server, and can be found at http://library.rit.edu/oajournals/index.php/jsesd

- Submissions can still be sent to the co-editors (1kq9999@ rit.edu \& tepnts@ rit.edu), or can be completed online at http://library.rit.edu/oajournals/index.php/jsesd/ author. Please note that you must first register as an author at the above journal web address in order to submit online.

- We improved production of our journal by recruiting a talented group led by Nicholas Paulus and Eric MacArthur of the RIT Wallace Library. This team has proved very competent in making sure that the journal is published with attention to quality. Through their guidance, the logistics maintaining the journal (from receipt of manuscripts, to layout, and publication) has improved dramatically. We are confident that we will be able to move a submitted article through the publication process in a timely manner for authors.

We continue to work diligently to improve JSESD and believe that the journal is now operating efficiently. One of the largest challenges to the journal remains the solicitation of manuscript submissions. As such, we are asking the journal's readership to assist us in advertising the journal. If you are familiar with individuals who might be interested in submitting a manuscript, please pass along the JSESD author link provided above.
We are especially interested in articles on science education for students with varying types of disabilities and at a full range of grade levels (K-12 and postsecondary).

We believe that there is a considerable amount of high quality scholarship that is being conduction in the field if science education for students with disabilities. We are pleased to be a mechanism for the dissemination of such efforts and are eager to grow to accommodate even more submissions.

The journal is interested in articles that fit into the following categories:

- Editorials

- Research Articles

- Teaching Techniques

- Product Reviews

- Cyber Links

As always, we appreciate your support in maintaining JSESD as a quality peer-reviewed journal.

Sincerely,

\section{Todd Pagano \\ QL L.K Quinsland}

Todd Pagano, Ph.D. \& L.K. Quinsland, Ph.D. Co-Editors, Journal of Science Education for Students with Disabilities

Rochester Institute of Technology/

National Technical Institute for the Deaf

About the JSESD cover:

Cathy Chou (Prof. of Imaging Arts \& Sciences at RIT/NTID) created the JSESD cover. The background DNA image was strategically chosen to symbolize the interplay of JSESD's readership; that of experts in various fields of disabilities along with experts in the disciplines of science. The two intertwined sides of the double helix backbone represent this relationship. The rungs of the DNA structure represent the various age groups (K-Postsecondary) of students upon which this journal focuses. 